\title{
The Impact of Body Mass Index Values on the Quality of Cardiopulmonary Resuscitation: A Manikin Study
}

\author{
Kadir Kucukceran ${ }^{1} \mathbb{D}$, Mustafa Kursat Ayranci ${ }^{1} \mathbb{D}$, Muhammet Rasit Ozer ${ }^{2}$ \\ ${ }^{1}$ Emergency Medicine, Necmettin Erbakan University, Meram Faculty of Medicine, Konya, Turkey. \\ ${ }^{2}$ Emergency Medicine, Karamanoglu Mehmetbey University, Faculty of Medicine, Karaman, Turkey. \\ Correspondence Author: Kadir Kucukceran \\ E-mail: kadirkucukceran@hotmail.com \\ Received: $30.07 .2020 \quad$ Accepted: 03.03.2021
}

\begin{abstract}
Objective: The purpose of this study is to assess the impact of body mass index (BMI) on the quality of cardiopulmonary resuscitation (CPR) by using a manikin.

Methods: 50 people composed of research assistants, intern doctors, emergency medical technicians and nurses who had previous cardiopulmonary resuscitation experience performed CPR on Laerdal Skillmeter Resusci-Anne ${ }^{\circledR}$ with SimPad manikin during the study. BMI data of participants were recorded and then the participanst were categorised as $\mathrm{BMI}<21$ and $\mathrm{BMI}>21$. Compression data obtained from the summary section of SimPAD QCPR were compared with the participants BMI values.

Results: 18 (36\%) out of 50 participants were male, while 32 (64\%) were female. $16(32 \%)$ out of 50 participants were in the slim group, while $34(68 \%)$ were in the normal group. Mean age of participants was calculated as $26.8 \pm 4.2$, and mean BMI as $22.56 \pm 3.32$. Mean compression depth in the slim group was significantly lower in comparison to the normal group (slim51.94 \pm 4.64, normal 55.79 $\pm 4.35, p=0.006)$. Compression ratiowith sufficient depth in the slim group was statistically lower than the normal group (slim $66.19 \pm 25.79, n o r m a l ~ 87.29 \pm 19.36, p=0.002$ ). A statistically significant positive correlation was found in the lineer regression analysis conducted between mean compression depth and BMI ( $r 2: 0.179, p=0.002)$. Moreover, a significant positive correlation was observed in the pearson correlation analysis of mean compression depth and BMI ( $r: 0.423, p=0.002)$.
\end{abstract}

Conclusion: As a result, it was found out that low BMI values are associated with low mean compression depth.

Keywords: Body Mass Index, cardiopulmonary resuscitation, basic cardiac life support.

\section{INTRODUCTION}

The prognosis of out-of hospital cardiac arrest (OHCA) is bad (1). Annually, itresults in300,000 people's death (2). The most important method to reduce this mortality is to increase the quality of cardiopulmonary resuscitation (CPR). It is know that simple changes such assufficient compression rate, sufficient compression depth, compression allowing for chest recoil, minimising compression interruptions and avoiding exteme ventilation increase survival rates by increasing CPR quality (3-5).

It has been stressed out that anthropometric variables have an impact on CPR quality (6). There are studies on the fact that anthropometric parameters affecting CPR include body weight, height, physical fitness and muscle power (7-9).

Our purpose is to compare data that could have an impact on CPR quality based on Body Mass Index (BMI) parameter by using a manikin.

\section{METHODS}

On June 5, 2020 this prospective simulation manikin study had an ethics committee approval by Necmettin Erbakan University Meram Medical Faculty Pharmaceutical and NonMedical Device Studies Ethical Committee by the decision number of 2020/2570.

Necmettin Erbakan University Meram Medical Faculty Pharmaceutical and Non-Medical Device Studies Ethical Committee by the decision number of 2020/2570

50 people composed of different professional groups working at our clinic (research assistants, intern doctors, emergency medical technicians and nurses) that have previous cardiopulmonary resuscitation experience, are knowledgeable about advanced cardiac life support and basic life support were randomly selected for the study on 
a voluntary basis. The participants signed a letter of consent for the study.

Laerdal Skillmeter Resusci-Anne ${ }^{\circledR}$ with SimPad manikin was used in the study. The participants were asked to perform nonstop compressionfor 2 minutes on the manikin. The manikin was introduced to the participants prior to compression. It was ensured that they had the sufficient time to perform CPR on the manikin. The manikin was planned to lie flat on its back on the ground during compression (supine position).

A metronom was used during compression to minimise the impact of compression rates on chest recoil (10). The metronom was arranged in a way to provide voice prompts 110 times per minute to achieve a rate of 100-120 compressions per minute as stated by the American Heart Association (AHA) and the European Resuscitation Council (ERC) guidelines $(11,12)$.

The data of CPR (after 2 minutes of compression) on the manikin were automatically generated by the summary section of SimPAD QCPR. Mean compression depth ( $\mathrm{mm})$, mean compression rate (compression/minute), compression ratio with a complete chest recoil (\%), compression ratio with sufficient depth (\%), compression ratio with sufficient rate(\%) values were obtained from the summary section of SimPAD QCPR. The manufacturing company defined that the sufficient depth was between 50 and $60(\mathrm{~mm})$ in reference to AHA and ERC guidelines. The manufacturing company defined sufficient rate was between 100 and 120 (compression/ minute) in reference to AHA and ERC guidelines. In addition, age, gender, profession, body mass index information of the participants were also recorded.

Though those below 20 are considered slim in BMI calculations (13), our study categorised BMI values as below and above 21 . The group with $\mathrm{BMI}<21$ was categorized as slim, while the group with $B M I \geq 21$ was categorized as normal. The reason we categorized it in this way was to reach a sufficient number of group populations to make statistical comparison. In addition, the participants were divided into 3 groups according to the cut-off BMI values of 21 and 23 (BMI<21, 21 $\leq \mathrm{BMI}<23$ and $\mathrm{BMI} \geq 23$ ).

The compression values on the manikin were compared between the groups. SPSS 20.0 (SPSS Inc., Chicago, IL) package was used to perform such a comparison and analyse the data statistically. Analyses of normality of the data were made by using histograms and Kolmogorov-Smirnov test.Nonnormally distributed quantitative data were stated as median (25\%-75\% quarters), while normally distributed quantitative variables were stated as mean \pm standard deviation (SD), and categorical variables were stated as frequency (percentage) [n (\%)]. The differences between two groups were investigated using the Mann-Whitney $U$ test in non-normally distributed quantitative variables, while Student's t-test was used for normally distributed quantitative variables. The differences between more than two groups were investigated using the Kruskal-Wallis test in non-normally distributed quantitative variables, while one-way Anova test was used for normally distributed quantitative variables. Dunnett's T3 test was used as a post hoc analysis test for non-normally distributed quantitative variables while Bonferroni test was used as a post hoc analysis test for normally distributed quantitative variables. We used the Bonferroni correction for multiple comparisons. Pearson correlation analysis and linear regression analysis were performed to assess the relationship between mean depth and BMI. $p<0.05$ value was accepted as statistically significant.

\section{RESULTS}

$18(36 \%)$ out of 50 participants were male, while 32 (64\%) were female. $18(36 \%)$ of the participants were assisstant doctors, 21 (42\%) were intern doctors, 10 (20\%) were nurses and 1 (2\%) was emergency medical technician (EMT). Mean $\pm S D$ age of the participants was $26.8 \pm 4.2$, while mean \pm SD BMI was found to be $22.56 \pm 3.32$.

Sixteen $(16(32 \%))$ of the participants were in the slim group and $34(68 \%)$ were in the normal group. Mean compression depth values in the slim group were significantly lower than the normal group (slim 51.94 \pm 4.64 , normal 55.79 \pm 4.35 , $\mathrm{p}=0.006$ ). Compression ratio with sufficient depth in the slim group was statistically significantly lower in comparison to the normal group (slim 66.19 \pm 25.79 , normal 87.29 \pm 19.36 , $\mathrm{p}=0.002$ ). Detailed information about compression data and comparison in between the groups (the cut-off BMI value of 21) are available in Table 1.

Table 1. Results of compression data between the groups

\begin{tabular}{|c|c|c|c|}
\hline & Slim (mean \pm SD) & $\begin{array}{c}\text { Normal } \\
\text { (mean } \pm \text { SD) }\end{array}$ & $p$ value \\
\hline $\begin{array}{l}\text { Mean Compression } \\
\text { Depth }(\mathrm{mm})\end{array}$ & $51.94 \pm 4.64$ & $55.79 \pm 4.35$ & 0.006 \\
\hline $\begin{array}{l}\text { Mean Compression Rate } \\
\text { (compression/minutes) }\end{array}$ & $111.63 \pm 1.66$ & $112 \pm 3.03$ & 0.647 \\
\hline $\begin{array}{l}\text { Compression Ratio with } \\
\text { Complete Chest Recoil (\%) }\end{array}$ & $85 \pm 14.63$ & $80.74 \pm 17.68$ & 0.406 \\
\hline $\begin{array}{l}\text { Compression Ratio with } \\
\text { Sufficient Depth (\%) }\end{array}$ & $66.19 \pm 25.79$ & $87.29 \pm 19.36$ & 0.002 \\
\hline $\begin{array}{l}\text { Compression Ratio with } \\
\text { Sufficient Rate (\%) }\end{array}$ & $94.75 \pm 6.12$ & $92.74 \pm 10.41$ & 0.478 \\
\hline
\end{tabular}

SD: Standard deviation

The number of participants with $\mathrm{BMI}<21$ was 16 (32\%), the number of participants with $21 \leq \mathrm{BMI}<23$ was 17 (34\%) and the number of participants with $B K I \geq 23$ was 17 (34\%). Mean compression depth of the $\mathrm{BMI} \geq 23$ was statistically higher than that of the $\mathrm{BMI}<21 \quad(\mathrm{BMI} \geq 23$ : $57.94 \pm 2.74, \mathrm{BMI}<21$ : $51.94 \pm 4.64, p<0.001)$. Mean compression depth of the $\mathrm{BMI} \geq 23$ was statistically higher than the $21 \leq \mathrm{BMI}<23$ (BMI $\geq 23$ : 57.94 $\pm 2.74,21 \leq B M l<23: 53.65 \pm 4.66, p=0.011)$. Compression ratio with sufficient depth of the $B M I \geq 23$ was statistically higher than that of the $\mathrm{BMI}<21 \quad(\mathrm{BMI} \geq 23$ : 96.41 \pm 6.73 , $B M \mid<21: 66.19 \pm 25.79, p<0.001)$. Detailed information about 
compression data and comparison in between the groups (the cut-off BMI values of 21 and 23) are available in Table 2.

Linear regression analysis of mean compression depth (dependant) and BMI (independent) showed a statistically significant $\left(r^{2}=0.179\right)$ positive relationship $(p=0.002)$.
'Expected mean compression depth $=40.893+0.606 * \mathrm{BMI}^{\prime}$ in line with the calculated regression formula. Moreover, a significant positive correlation was observed between mean compression depth and BMI in the Pearson's correlation analysis $(r=0.423, p=0.002)$.

Table 2. Results of compression data between the groups (the cut-off BMI values of 21 and 23)

\begin{tabular}{|c|c|c|c|c|c|c|c|}
\hline & $\begin{array}{c}\mathrm{BMI}<21 \\
(\text { mean } \pm \mathrm{SD})\end{array}$ & $\begin{array}{l}21 \leq \mathrm{BMl}<23 \\
(\text { mean } \pm S D)\end{array}$ & $\begin{array}{c}\text { BMI } \geq 23 \\
\text { (mean } \pm S D)\end{array}$ & $p$ value & p $(I-I I)^{*}$ & p $(I-I I I)^{* *}$ & p (II-III) $)^{* * *}$ \\
\hline $\begin{array}{l}\text { Mean Compression } \\
\text { Depth }(\mathrm{mm})\end{array}$ & $51.94 \pm 4.64$ & $53.65 \pm 4.66$ & $57.94 \pm 2.74$ & $<0.001$ & 0.713 & $<0.001$ & 0.011 \\
\hline $\begin{array}{l}\text { Mean Compression } \\
\text { Rate(compression/ } \\
\text { minutes) }\end{array}$ & $111.63 \pm 1.66$ & $112.06 \pm 3.5$ & $111.94 \pm 2.58$ & 0.894 & 0.999 & 0.999 & 0.999 \\
\hline $\begin{array}{l}\text { Compression Ratio with } \\
\text { Complete Chest Recoil } \\
(\%)\end{array}$ & $85 \pm 14.63$ & $81.29 \pm 18.17$ & $80.18 \pm 17.71$ & 0.698 & 0.999 & 0.999 & 0.999 \\
\hline $\begin{array}{l}\text { Compression Ratio with } \\
\text { Sufficient Depth (\%) }\end{array}$ & $66.19 \pm 25.79$ & $78.18 \pm 23.48$ & $96.41 \pm 6.73$ & $<0.001$ & 0.294 & $<0.001$ & 0.037 \\
\hline $\begin{array}{l}\text { Compression Ratio with } \\
\text { Sufficient Rate (\%) }\end{array}$ & $94.75 \pm 6.12$ & $92.24 \pm 11.39$ & $93.24 \pm 9.66$ & 0.743 & 0.999 & 0.999 & 0.999 \\
\hline
\end{tabular}

SD: standard deviation; *: $p$ values are obtained from the paired comparisons of parameters of BMI<21 and $21 \leq B M K<23$ groups; **: $p$ values are obtained from the paired comparisons of parameters of $B M I<21$ and $B M I \geq 23$ groups; ***: $p$ values are obtained from the paired comparisons of parameters of $21 \leq B M I<23$ and $B M I \geq 23$ groups

\section{DISCUSSION}

We have to take the necessary measures to perform quality cardiopulmonary resuscitation. Anthropometric variables are among one of the factors that will have an impact on CPR's quality. We compared compression data that will affect CPR quality with BMI values in our study.

Mean depth and compression with sufficient depth ratios were significantly lower in the slim group with BMI values below 21 in comparison to the other group. In their manikin study involving 102 nursing students, Roh et al. pointed out that mean depth measurements of the group with BMI values below 18.5 were significantly lower than the other groups (14). The data of the study are compatible with the literature.

Linear regression analysis indicated a significant positive correlation between BMI and mean compression depth data. At the CPR study conducted by $\mathrm{Oh}$ et al. with 107 medical students on a manikin, a positive correlation was found between body weight and mean compression depth (15). Regression equation in the same study revealed that rescuers should weigh minimum $70.5 \mathrm{~kg}$ to achieve a chest compression depth of $50 \mathrm{~mm}$. The data of the study are compatible with the literature.

A significant positive correlation was observed between BMI and mean depth in our study. The highest positive correlation was found between mean depth and body weight in the correlation analysis of anthropometric variables and CPR data in the CPR study by $\mathrm{Oh}$ et al. conducted with 107 medical students on a manikin (15). The same study showed a significant positive correlation between BMI and mean depth. Similarly, the study of Méndez-Martínez et al. including 112 nursing and physiotherapy students found out a significant positive relationship between BMI and weight (16). The data of the study are compatible with the literature.

The study by Contri et al. where 333 participants performed CPR on a manikin indicated that people who are heavier, who have a greater BMI achieve less chest recoil (6). In our study, chest recoil ratio was found out to be higher in the slim BMI group but the difference in between was not statistically significant. The importance of achieving higher chest recoil decreases due to lack of sufficient depth.

\section{CONCLUSION}

As a conclusion, it was found out that low BMI values are associated with low mean compression depth. Effective trainings to achieve sufficient mean depth should be provided as out-of-hospital arrest patients for whom a low mean depth CPR is performed, have a higher mortality $(17,18)$. However, it is observed that low weighing individuals could not achieve the sufficient chest compression depth though they have participated in effective CPR trainings (19). Therefore, we should be more careful and sensitive when we provide CPR trainings to low weighing professionals $(14,19)$. We are in the opinion that we should be more sensitive in terms of CPR training of professionals with low BMI values and besides, professionals with higher BMI values should be responsible for compression during CPR as long as there is a sufficient number of professionals to do so. 
The limitation of the study could be considered as the low number of participants. The low number of participants especially in the slim group constitutes another limitation as it reduces the power of statistical comparison. The factors such as being a manikin study, failure to evaluate the survival rates can be considered as another limitations of our study. A separate limitation is that compression data cannot be compared according to gender. Because male gender with low BMI values may be different from female.

\section{REFERENCES}

[1] Sasson C, Rogers MA, Dahl J, Kellermann AL. Predictors of survival from out-of-hospital cardiac arrest: a systematic review and meta-analysis. Circ Cardiovasc Qual Outcomes 2010;3(1):63-81.

[2] Roger VL, Go AS, Lloyd-Jones DM, Adams RJ, Berry JD, Brown TM, Carnethon MR, Dai S, de Simone G, Ford ES, Fox CS, Fullerton HJ, Gillespie C, Greenlund KJ, Hailpern SM, Heit JA, Ho PM, Howard VJ, Kissela BM, Kittner SJ, Lackland DT, Lichtman JH, Lisabeth LD, Makuc DM, Marcus GM, Marelli A, Matchar DB, McDermott MM, Meigs JB, Moy CS, Mozaffarian D, Mussolino ME, Nichol G, Paynter NP, Rosamond WD, Sorlie PD, Stafford RS, Turan TN, Turner MB, Wong ND, WylieRosett J. Heart disease and stroke statistics-2011 update: a report from the American Heart Association. Circulation 2011;123(4):18-209.

[3] Rea TD, Helbock M, Perry S, Garcia M, Cloyd D, Becker L, Eisenberg M. Increasing use of cardiopulmonary resuscitation during out-of-hospital ventricular fibrillation arrest. Circulation 2006;114(25):2760-2765.

[4] Kellum MJ, Kennedy KW, Ewy GA. Cardiocerebral resuscitation improves survival of patients with out-of-hospital cardiac arrest. Am J Med 2006;119(4):335-340.

[5] Bobrow BJ, Clark LL, Ewy GA, Chikani V, Sanders AB, Berg RA, Richman PB, Kern KB. Minimally interrupted cardiac resuscitation by emergency medical services for out-ofhospital cardiac arrest. JAMA 2008;299(10):1158-1165.

[6] Contri E, Cornara S, Somaschini A, Dossena C, Tonani M, Epis F, Zambaiti E, Fichtner F, Baldi E. Complete chest recoil during laypersons' CPR: Is it a matter of weight? Am J Med 2017;35(9):1266-1268.

[7] Hasegawa T, Daikoku R, Saito S, Saito Y. Relationship between weight of rescuer and quality of chest compression during cardiopulmonary resuscitation. J Physiol Anthropol 2014;33(1):1-7.

[8] Hansen D, Vranckx P, Broekmans T, Eijnde BO, Beckers W, Vandekerckhove $\mathrm{P}$, Broos $\mathrm{P}$, Dendale P. Physical fitness affects the quality of single operator cardiocerebral resuscitation in healthcare professionals. Eur J Emerg Med 2012;19(1):28-34.

[9] Ock S-M, Kim Y-M, hye Chung J, Kim SH. Influence of physical fitness on the performance of 5-minute continuous chest compression. Eur J Emerg Med 2011;18(5):251-256.

[10] Lee SH, Ryu JH, Min MK, Kim YI, Park MR, Yeom SR, Han SK, Park SW. Optimal chest compression rate in cardiopulmonary resuscitation: a prospective, randomized crossover study using a manikin model. Eur J Emerg Med 2016;23(4):253-257.

[11] Kleinman ME, Brennan EE, Goldberger ZD, Swor RA, Terry M, Bobrow BJ, Gazmuri RJ, Travers AH, Rea T. Part 5: Adult basic life support and cardiopulmonary resuscitation quality: 2015 American Heart Association guidelines update for cardiopulmonary resuscitation and emergency cardiovascular care. Circulation 2015;132(18_suppl_2):S414-S435.

[12] Perkins GD, Handley AJ, Koster RW, Castrén M, Smyth MA, Olasveengen T, Monsieurs KG, Raffay V, Gräsner JT, Wenzel $V$, Ristagno G, Soar J. Adult basic life support and automated external defibrillation section Collaborators. European Resuscitation Council Guidelines for Resuscitation 2015: Section 2. Adult basic life support and automated external defibrillation. Resuscitation 2015;95:81-99.

[13] Grodstein F, Goldman MB, Cramer DW. Body mass index and ovulatory infertility. Epidemiology 1994:247-250.

[14] Roh YS, Lim EJ. Factors influencing quality of chest compression depth in nursing students. Int J NursPract 2013;19(6):591-595.

[15] Oh JH, Kim CW. Relationship between chest compression depth and novice rescuer body weight during cardiopulmonary resuscitation. Am J Med 2016;34(12):2411-2413.

[16] Méndez-Martínez C, Martínez-Isasi S, García-Suárez $M$, Peña-Rodríguez MA, Gómez-Salgado J, Fernández-García D. Acquisition of knowledge and practical skills after a brief course of BLS-AED in first-year students in nursing and physiotherapy at a Spanish university. Int J Environ Res Public Health 2019;16(5):766-766.

[17] Edelson DP, Abella BS, Kramer-Johansen J, Wik L, Myklebust H, Barry AM, Merchant RM, Hoek TL, Steen PA, Becker LB. Effects of compression depth and pre-shock pauses predict defibrillation failure during cardiac arrest. Resuscitation 2006;71(2):137-145.

[18] Kramer-Johansen J, Myklebust H, Wik L, Fellows B, Svensson L, Søreb $\varnothing \mathrm{H}$, Steen PA. Quality of out-of-hospital cardiopulmonary resuscitation with real time automated feedback: a prospective interventional study. Resuscitation 2006;71(3):283-292.

[19] Krikscionaitiene A, Pranskunas A, Stasaitis K, Dambrauskiene M, Jasinskas N, Dambrauskas Z, Vaitkaitiene E, Vencloviene J, Vaitkaitis D. Magical manoeuvre: a 5-s instructor's intervention helps lightweight female rescuers achieve the required chest compression depth. Eur J Emerg Med 2014;21(6):424-428.

How to cite this article: Kucukceran K, Ayranci MK, Ozer MR. The Impact of Body Mass Index Values on the Quality of Cardiopulmonary Resuscitation: A Manikin Study. Clin Exp Health Sci 2021; 11: 269-272. DOI: 10.33808/clinexphealthsci.775972 